\title{
Investigations on Structural Safety of Office Room Based on Fire Simulation and Transient Heat Transfer Analysis
}

\author{
Ah Young An, Eun Mi Ryu, Hee Sun Kim \\ Department of Architectural Engineering, Ewha Woman's University, Seoul, Korea \\ Email: aay0522@hanmail.net, hskim3@ewha.ac.kr
}

Received May 2014

\begin{abstract}
This study aims at investigating heat propagations inside the structural members due to fire using fire simulation and transient heat transfer analysis. Toward that goal, fire simulation and transient heat transfer analysis for a 5-story building are carried out sequentially using Fire Dynamics Simulator (FDS) and ABAQUS 6.10-3, respectively. As results from fire simulation, temporal temperature information is obtained depending on various locations of the building, which is used as boundary condition for the structural elements generated in transient heat transfer analysis. Predictions from the transient heat transfer analysis show that the structural members are exposed spatially non-uniform temperatures which can cause significant eccentric deformation and aceleration of structural damages.
\end{abstract}

\section{Keywords}

Fire Simulation, Heat Transfer, Structural Safety, Fire

\section{Introduction}

Even though concrete is well known as thermal resistant material, concrete structures exposed to severe fire accident show significant degradation of structural capacities and lead to building collapse. Since performing experiments for safety evaluation of fire damaged structures requires huge cost and time, there is a need for quantitative modeling approaches that can evaluate structural safety based on accurate predictions of fire and heat propagations.

Fire simulation tools such as CFAST, JASMINE, SOFIE, FiRECAM and FDS, have developed by research laboratories and academic institutions in many counties. Among them, this study uses Fire Dynamics Simulator (FDS) developed at the Building and Fire Research Laboratory (BFRL) at the National Institutes of Standards and Technology (NIST) [1] [2]. The program calculates the temperature, density, pressure, velocity, and chemical composition within each numerical grid cell at each discrete time step. It computes the temperature, heat flux, and mass loss rate of the enclosed solid surfaces. The FDS code is formulated based on Computational Fluid Dynamics (CFD) of fire-driven fluid flow. The FDS numerical solution can be carried out using either a Direct Numerical Simulation (DNS) method or Large Eddy Simulation (LES). The latter is not severely limited in grid

How to cite this paper: An, A.Y., Ryu, E.M. and Kim, H.S. (2014) Investigations on Structural Safety of Office Room Based on Fire Simulation and Transient Heat Transfer Analysis. World Journal of Engineering and Technology, 2, 20-26. 
size and time step as the DNS method. In addition to the classical conservation equations considered in FDS, including mass species momentum and energy, thermodynamics-based state equation of a perfect gas is adopted along with chemical combustion reaction for a library of different fuel sources. FDS has a visual post-processing image simulation program named "smokeview". In FDS, the Heat Release Rate (HRR) per unit area of a fire source can be prescribed and numerically characterized directly avoiding calculating the heat release using chemical combustion reaction. Therefore, it is important to find accurate HRR curve or fire load according to various types and amount of fire sources. Madrzykowski [3], Karlsson and Quintiere [4], Au [5], and Chow [6] reported experimental or numerical studies about HRR curves in various fire environments. Especially, Madrzykowski [3] performed fire experiment on office room with different work station configurations and measured HRR and radiation during fire. In the study, peak HRR of work station ranged from 2.8 MW to 6.9 MW and growth rate changed from "slow-medium" to "fast-ultra fast" phase.

Since the fire simulation focuses on predicting fire propagations based CFD of fire-driven fluid flow and has limitation on predicting temperature distribution inside the structural members, transient heat analysis needs to be performed in order to evaluate safety of fire damaged structures. Choi [7], Choi, Kim, Haj-Ali [8], and Choi, Haj-Ali, Kim [9] proposed sequentially coupled analytical methods for predicting temperature distributions and structural behaviors of structural members considering temperature dependent thermal and mechanical properties of concrete. In their studies, the proposed methods were applied to simulate reinforced concrete beams, steel-concrete building, and bridge under fire for the model validation and showed good agreements. Harmathy [10] [11] provided properties of building materials such as concrete, steel, etc., at elevated temperatures and reported that the properties of different concrete are within upper and lower bounds depending on aggregates, admixtures, and mix proportions. In addition, Choi [9] performed parametric analyses, in order to examine effect of the wide ranges of material properties on thermal and structural behaviors of fire damaged concrete structures.

This paper aims at evaluating safety of structural members of office rooms based on fire simulation and transient heat transfer analysis. Towards that goal, fire simulating approaches by investigating effect of various influencing parameters on fire propagations. Then, the spatial-temporal temperature information obtained from the fire simulation is used as boundary condition of structural members for transient heat transfer analysis. Finally, safety of the structural members is evaluated based on temperature distributions predicted from transient heat transfer analysis considering temperature dependent thermal and mechanical properties of concrete.

\section{Modeling Approach}

\subsection{Fire Simulation Approach}

In this study, fire simulation is performed on a 5-story building located in Seoul, South Korea. The structural system of the building is framed structure made of normal strength concretes reinforced by deformed steel bars. Since fire simulation requires relatively long computational time, only two out of five stories are modeled with an assumption that fire is initiated from a room located on a fourth floor shown in Figure 1. With the assumption, only fourth and fifth floor are modeled because heats tend to be propagated toward the upper floor. Based on architectural and structural plans, elements for walls, slabs, and ceilings are generated. For walls and ceilings, concrete and insulation material properties are included in the model and slabs are considered as reinforced concrete with $150 \mathrm{~mm}$ of thickness. Doors and windows are assumed as open and $2.17 \mathrm{~m} / \mathrm{s}$ of northwestern winds are prescribed.

In order to investigate effect of parameters on fire and heat propagation, variables for fire simulations are chosen as period of fire, size of inflammable materials and fire growth phase. Fire simulations are performed for 30 and 60 min to examine effect of fire period to heat propagation. In addition, sizes of inflammable materials are $15 \mathrm{~m}^{2}, 42 \mathrm{~m}^{2}$, and $210 \mathrm{~m}^{2}$, determined by size of typical work stations, one room, and five rooms, respectively. However, area of hallway is not included in the size of inflammable materials because possible fire source is not stacked in hallway by law. From the fire simulation, temporal-temperatures are obtained at different locations of the rooms and hallway of fourth and fifth floor. Finally, fire loads are prescribed in a form of heat release rate (HRR) curve, and the time to reach steady phase of HRR curve determines whether the fire is slow, medium or fast growth phase. Figure 2 shows two possible HRR curves for office building, based on the literature reviews [4]. In addition, maximum value of the HRR curve is prescribed as $876.19 \mathrm{~kW} / \mathrm{m}^{2}$, according to Madrzykowski’s study [3]. 


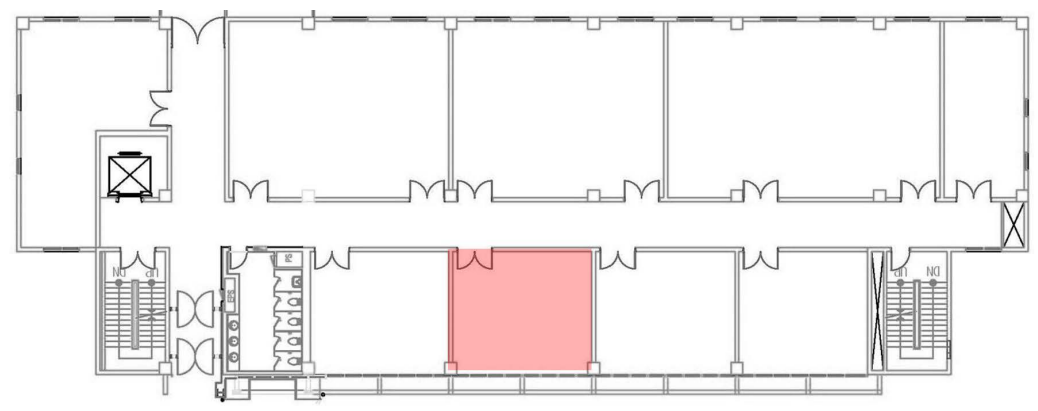

Figure 1. Floor plan (Marked area: location of fire initiation).

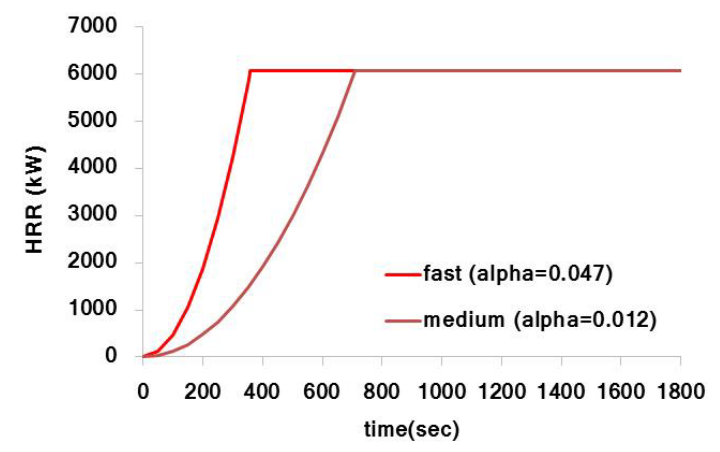

Figure 2. Heat release rate (HRR) curve.

\subsection{Transient Heat Transfer Analysis}

Transient heat transfer analysis is performed to predict temperature distributions between and inside the structural members. In the study, commercial finite element (FE) analysis software, ABAQUS 6.10-3 is used to generate FE elements of the fire initiated compartment which size is $8.4 \mathrm{~m} \times 7.2 \mathrm{~m}$ in area and $2.4 \mathrm{~m}$ in height. The FE model includes structural members, such as four columns, eight girders, two beams, and a slab. According to structural plans, cross section of the columns is $500 \mathrm{~mm} \times 500 \mathrm{~mm}$. In addition, cross sections of the girders and the beams are $650 \mathrm{~mm} \times 350 \mathrm{~mm}$ and $550 \mathrm{~mm} \times 350 \mathrm{~mm}$, respectively. The thickness of the slab is $150 \mathrm{~mm}$. The initial temperature is prescribed as $20^{\circ} \mathrm{C}$, and the temporal-spatial temperatures obtained from the fire simulation are prescribed using in-house written code in Fortran language to the surfaces of the structural members exposed to the fire. Prescription of the temporal-spatial temperature information is important, because it is observed from fire simulation that temperatures are not non-uniform even within one span depending on the locations. Therefore, the prescribed temperature varies along $\mathrm{x}, \mathrm{y}$, and $\mathrm{z}$ axis depending on the distance from the location of fire source. As results, time to reach $500^{\circ} \mathrm{C}$ at location of reinforcing steel bars is examined at different structural members.

\section{Results}

\subsection{Fire Simulation}

Figure 3 illustrates time-temperature curve obtained at location of fire source depending on medium and fast fire growth phases. As shown, there is no significant difference of time-temperature curves due to fire growth phase. Especially, time-temperature curves in range of 0 - $800 \mathrm{sec}$ show almost identical, even though times to reach maximum HRR value are about 350 sec and 700 sec for fast and medium growth phase, respectively. In the early stage of fire, temperature around fire source increases drastically within less than 200 sec until it reaches $900^{\circ} \mathrm{C}-1000^{\circ} \mathrm{C}$. After reaching $900^{\circ} \mathrm{C}-1000^{\circ} \mathrm{C}$, time-temperature curve becomes steady state with only slight increase. Therefore, it can be also seen that the increase of temperature depending on time period of fire accident is not critical after $200 \mathrm{sec}$, with a condition that the fire simulation doesn't include decay phase of HRR or fire suppression.

Figure 4 illustrates time-temperature curves predicted from different locations shown in Figure 5. As shown, 


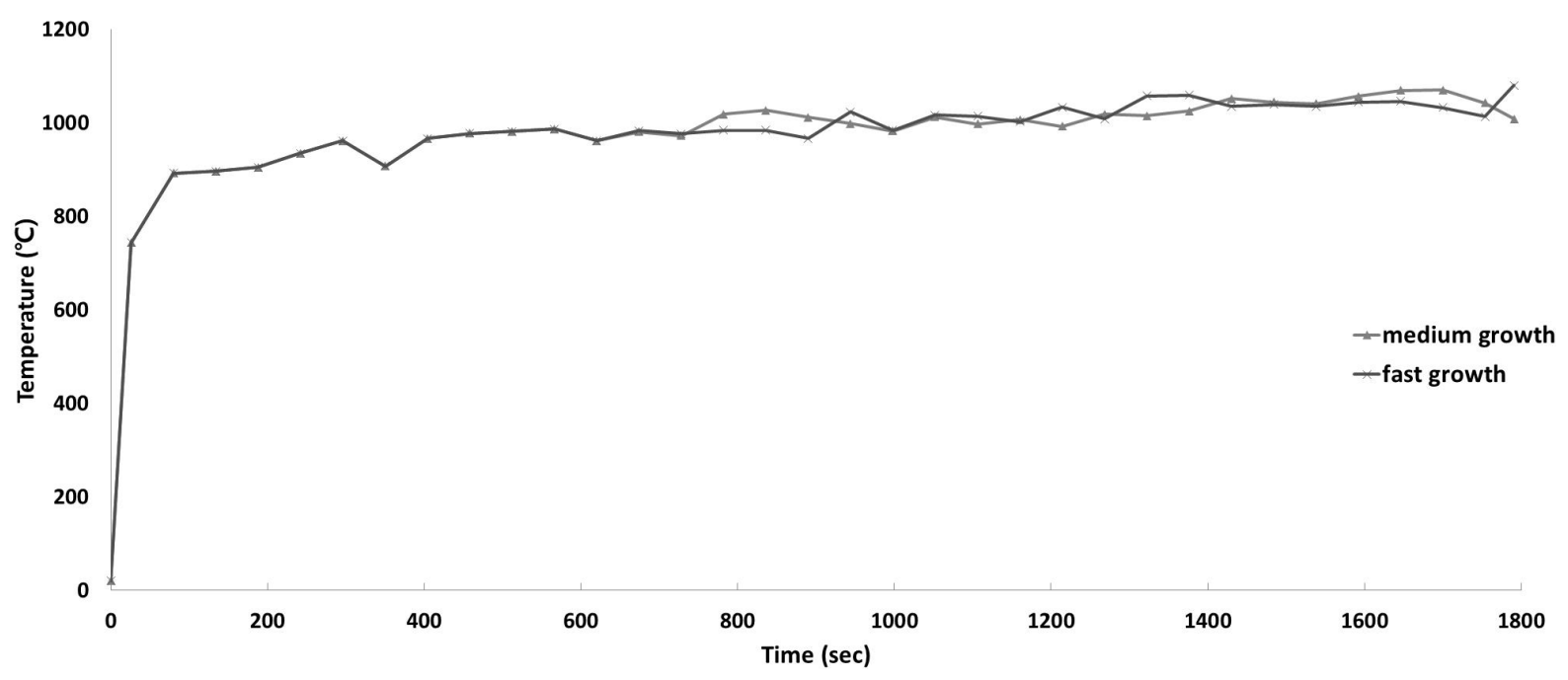

Figure 3. Time-temperature curve depending on fire growth phase.

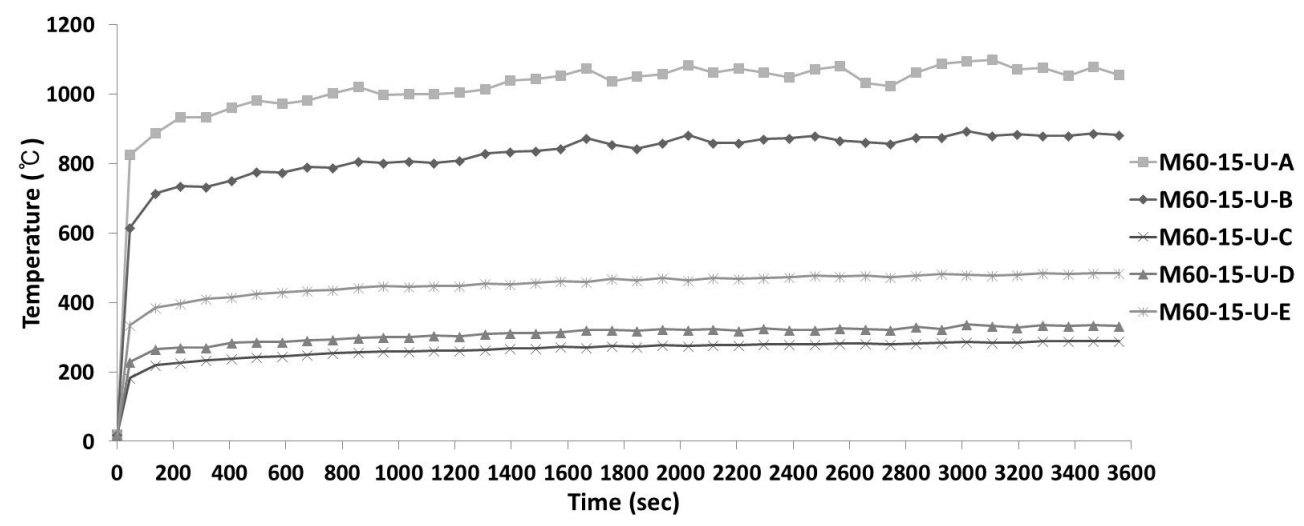

Figure 4. Time-temperature curve at different location.

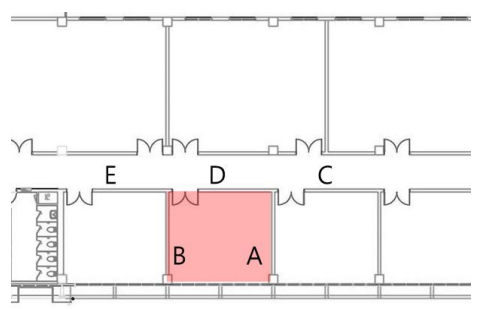

Figure 5. The location of sensor.

temperature difference within the fire initiated room is about $200^{\circ} \mathrm{C}$. Maximum temperature of hallway varies from $200^{\circ} \mathrm{C}-400^{\circ} \mathrm{C}$, and the higher temperature occurs in the west side of the hallway (E) compared to right side of the hallway (C). Because the fire simulation is modeled with northwestern winds with a speed of 2.17 $\mathrm{m} / \mathrm{s}$ referring to the local weather report, temperatures are transferred towards the west. In addition, maximum temperatures obtained at different locations depending on sizes of inflammable materials are illustrated in Figure 6. When the model includes inflammable materials located in the rooms nearby fire sources, maximum temperature at hallway (D) increases more than about $700^{\circ} \mathrm{C}$, compared to the case that the inflammable materials is located only at the corner of the room. However, it is interesting to note that maximum temperatures of fire initiated room are not sensitive to size of inflammable materials relative to maximum temperatures of hallway. Figure 7 also shows time-temperature curves predicted at different heights of the model. Since temperature tends to move upward due to convection, temperature at $2 \mathrm{~m}$ above the fire source is about $200^{\circ} \mathrm{C}$ higher than 
the temperatures right above the fire source. However, it seems that temperatures are not transferred to the upper floor until 30 min after fire initiation due to insulation effect of the concrete slab.

\subsection{Transient Heat Transfer Analysis}

Figure 8 shows temperature distributions predicted from transient heat transfer analysis prediction along with

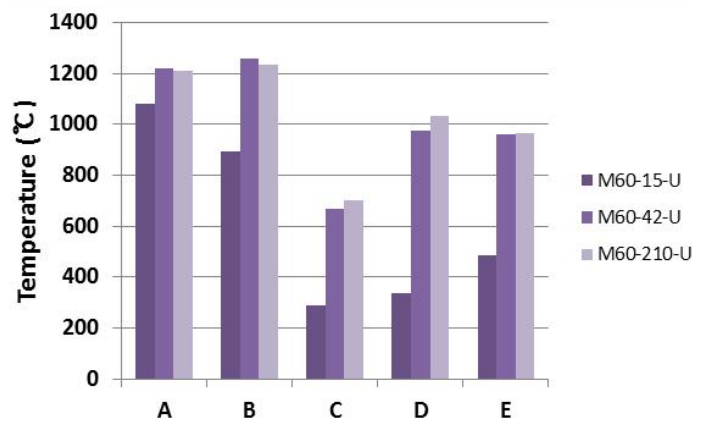

Figure 6. Maximum temperature depending on area of fire source.

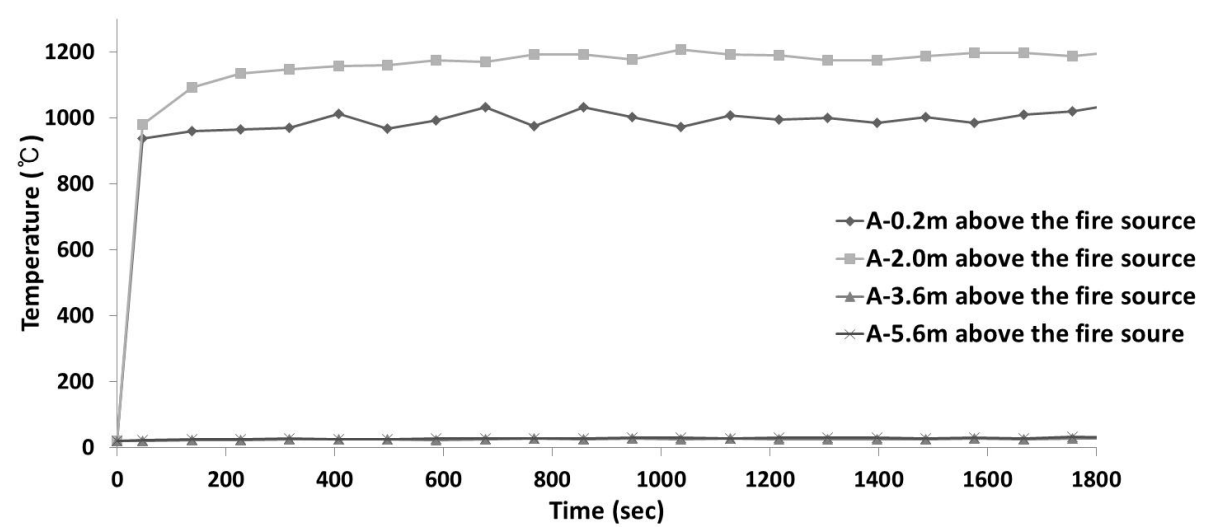

Figure 7. Time-temperature curve obtained at different height above the fire source.

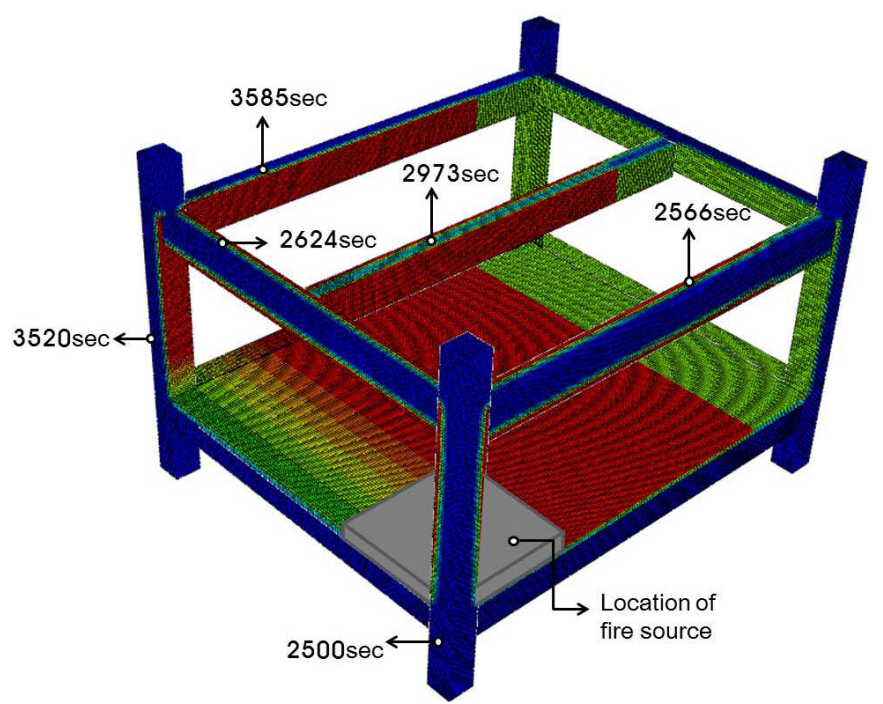

Figure 8. Predictions from transient heat transfer analysis with times to reach $500^{\circ} \mathrm{C}$. 
times for the temperature inside the cover thickness to reach at $500^{\circ} \mathrm{C}$. It is important to check if the inner temperature reaches at $500^{\circ} \mathrm{C}$, because structural members lose structural capacity if the temperature exceeds $500^{\circ} \mathrm{C}$ according to Choi's study [12]. In addition, compressive strength of normal strength concrete degrades about $50 \%$ at $500^{\circ} \mathrm{C}$ [10] [11]. From the fire simulation, the temperatures predicted from M-60-210 model are used in the transient heat transfer analysis, because the case is the most realistic and critical. As seen from Figure 8, temperatures inside the cover thickness for the most of structural members reach $500^{\circ} \mathrm{C}$ at $2500-3600 \mathrm{sec}$ after fire initiation. Since the prescribed temperature on the surfaces of the structural members varies according to the results predicted from fire simulation, times to reach $500^{\circ} \mathrm{C}$ varies depending on the locations and the structural members. Among the structural members, upper section of the column closed to fire source reaches $500^{\circ} \mathrm{C}$ at around $2500 \mathrm{sec}$, which denotes that the column nearby the fire source is the most critical in terms of structural safety. Girders are the next critical members, because three surfaces are exposed to high temperatures. However, temperatures inside the slab do not reach $500^{\circ} \mathrm{C}$ during 1 hour of fire, since the temperatures are relatively low in the bottom and the hallway. The predictions denote that partial surfaces of the structural members are subjected to non-uniform temperatures which can lead significant eccentric deformation and acceleration of structural damages.

\section{Conclusion}

This study includes fire simulation and transient heat transfer analysis to investigate heat propagations inside the structural members due to fire. In the fire simulation, parametric studies for the effect of fire growth phase and size of inflammable materials on time-temperature curves are included. Also, temperatures are examined at different locations and heights of the fire initiated room and hallway. As results, it is shown that temperature increases drastically in the beginning of fire, then maintains its maximum temperature for the rest of fire. Medium and fast growth phases do not cause differences on time-temperature curves. However, temperature increases with the size of inflammable materials, and the more significant result is examined in the hallway. In the transient heat transfer analysis, temporal-spatial temperature information obtained from the fire simulation is used as boundary conditions of the structural members and time to reach $500^{\circ} \mathrm{C}$ inside the cover thickness is examined to investigate structural safety from the predicted heat propagations. The results from the transient heat transfer analysis show that location of cover thickness for most structural members reaches $500^{\circ} \mathrm{C}$ within one hour of fire, except for a floor slab. Among the members, upper part of the column located nearby fire source reaches $500^{\circ} \mathrm{C}$, followed by lower part of the girder attached to the column. The predicted results show that not only the structural members reach $500^{\circ} \mathrm{C}$ at different time level, also they are exposed to spatially non-uniform temperatures due to convection, which can cause significant eccentric deformation and acceleration of structural damages.

\section{Acknowledgements}

This research was supported by Basic Science Research Program through the National Research Foundation of Korea (NRF) funded by the Ministry of Science, ICT \& Future Planning ((No. NRF-2013R1A2A2A04014772).

\section{References}

[1] McGrattan, K. (2005) Fire Dynamics Simulator (Version 4) Technical Reference Guide, NIST Special Publication 1018, National Institute of Standards and Technology (NIST).

[2] McGrattan, K., Forney, G.P., Floyd, J.F., Hostikka, S. and Prasad, K. (2002) Fire Dynamics Simulator (Version 3) —User's Guide, NISTIR 6784, National Institute of Standards and Technology (NIST).

[3] Madrzykowski, D. (1996) Office Work Station Heat Release Rate Study; Full Scale vs. Bench Scale, Interflam. Proceedings of 7 th International Interflam Conference.

[4] Karlsson, B. and Quintiere, J.G. (2000) Enclusre Fire Dynamics. CRC Press LLC 2000 N.W. Corporate Blvd., Boca Raton.

[5] Au, S.K., Wang, Z. and Lo, S. (2007) Compartment Fire Risk Analysis by Advanced Monte Carlo Simulation. Engineering Structures, 29, 2381-2390. http://dx.doi.org/10.1016/j.engstruct.2006.11.024

[6] Chow, A.U. (2012) Concerns on Estimating Heat Release Rate of Design Fires in Fire Engineering Approach. International Journal on Engineering Performance-Based Fire Codes, 11, 11-19.

[7] Choi, J. (2008) Concurrent Fire Dynamics Models and Thermomechanical Analysis of Steel and Concrete Structures, 
Ph.D. Thesis, Georgia Institute of Technology, USA.

[8] Choi, J., Kim, H.S. and Haj-Ali R.M. (2010) Integrated Fire Dynamic and Thermomechanical Modeling Framework for Steel-Concrete Composite Structures. Steel and Composite Structures, 10, 129-149. http://dx.doi.org/10.12989/scs.2010.10.2.129

[9] Choi, J., Haj-Ali, R.M. and Kim, H.S. (2012) Integrated Fire Dynamic and Thermomechanical Modeling of a Bridge under Fire. Structural Engineering and Mechanics, 42, 815-829. http://dx.doi.org/10.12989/sem.2012.42.6.815

[10] Harmathy, T.Z. (1983) Properties of Building Materials at Elevated Temperatures. DRP Paper No. 1080 of the Division of Building Research.

[11] Harmathy, T.Z. (1988) Properties of Building Materials in SFPE Handbook of Fire Protection Engineering. In: Dinenno, P.J., Ed., Section 1, Chapter 26, 378-391.

[12] Choi, E.G. (2008) Performance Assessment of High Strength Concrete Members Subjected to Fire. Ph.D. Thesis, Ewha Womans University, South Korea. 